Trrso de Molina, Comedias, vol. II (Averigüelo Vargas y $\mathrm{El}$ amor médico), edición, prólogo y notas de Alonso Zamora Vicente y María Josefa Canellada de Zamora. Colección Clásicos castellanos, vol. I 3 I. Espasa-Calpe, Madrid, I947. xvi $+4+269$ págs.

Tirso de Molina, Por el sótano y el torno, edición, prólogo y notas de Alonso Zamora Vicente. Instituto de Filología, Sección Románica, Buenos Aires, 1949. 217 págs.

En la primera de estas obras los editores no dicen por qué han escogido esas dos piezas, que no son ciertamente de las mejores de Tirso. Claro está que muestran la pericia de Tirso para estructurar y caracterizar, pero, en nuestra opinión, El celoso prudente, El melancólico o una obra de la trilogía de la Santa Juana y de la de los Pizarros habrían mostrado mejor las dimensiones de Tirso como dramaturgo. Quizá los editores se propongan publicar otros volúmenes.

Parece que la casa editorial limitó el tamaño del libro. $Y$ sin embargo no puede dejar de desilusionarnos el prólogo, que no consta más que de diez páginas. Poco más de dos páginas se dedican a los hechos más importantes de la vida de Tirso; las demás se ocupan del ambiente portugués de la obra, de sus bases históricas y, brevemente, de su estilo. No se da la lista de las obras de Tirso que se desarrollan en Portugal, no se intenta explicar en qué momento se familiarizó Tirso con ese país, ni se alude para nada al hecho de que esto constituye uno de los problemas de la biografía del dramaturgo. Las notas, en cambio, son abundantes, como lo muestran los 227 puntos tratados en el Índice de voces comentadas.

En la página $\mathrm{x}$ se menciona, como si fuera obra indudable de Tirso, Siempre ayuda la verdad, cuando hay en realidad grandes dudas acerca de quién fué su autor. En la misma página los editores hablan de la "última comedia" de Tirso, Las quinas de Portugal, y en la nota I afirman que "esta comedia se conserva autógrafa en la Biblioteca $\mathrm{Na}$ cional de Madrid" remitiendo a "Juan A. Tamayo, El manuscrito de las Quinas de Portugal", en RevBN, 1942. El título del artículo es Los manuscritos de "Las quinas de Portugal", y en él Tamayo ha demostrado, sin lugar a dudas, que el "manuscrito autógrafo" no contiene una palabra de mano de Tirso.

Se da el Resumen de la versificación de cada pieza, junto con el porcentaje de los diversos metros de cada acto y de toda la obra. En el Resumen total de El amor médico sería mejor poner, en lugar de "endecasílabos - 56- I.03\%" y "heptasílabos - 56- I.03\%", silva $\mathrm{I}^{\circ}-\mathrm{I} \mathrm{I} 2-2.06 \%$.

Los textos de las comedias parecen ser excelentes, a excepción de las mayúsculas y de la omisión de algunas diéresis. Hartzenbusch puso siempre con mayúscula Don, Doña, Magestad, Alteza, y, cuando no iban seguidos de nombre, Infanta e Infante. Los señores Zamora no han procurado la uniformidad, ni siquiera en dos versos sucesivos. En Averigüelo Vargas, III, xx, por ejemplo, leemos dos veces Don Ramiro, tres veces don Dionís, tres veces Doña Sancha, una vez Don Duarte 
y cinco veces infanta; en III, III, v y vi aparece siete veces Infanta y seis Don Dionís. Hartzenbusch escribía siempre Vuexcelencia. En el presente texto de $E l$ amor médico leemos Vuexcelencia en el verso $\mathrm{r}_{3} 6_{3}$, Vueselencia en los versos igor y 1929 y vuescelencia en los versos 2472 y $248 \mathrm{I}$.

En El amor médico, II, Iv los editores suponen, basándose en Hartzenbusch, que Tello y Delgado permanecen en escena, a pesar de que no dicen nada, ni se les dirige la palabra, ni se habla de ellos. Una nota debería haber aclarado los fundamentos de esta suposición. Los versos $13^{8} 3^{-1} 393$ de la misma escena se atribuyen en la edición de Hartzenbusch a don Martín, y en la presente edición a don Íñigo; también aquí haría falta una nota, puesto que en este texto don Martín no aparece hasta en la escena vi y permanece a lo largo de 430 versos sin pronunciar una sola palabra. Aparece de nuevo en III, I, II y xx, y sólo dice un verso y medio en la escena II. Otro personaje, Machado, del cual no sabemos nada, está en escena en I, n-v (478 versos) y sólo dice un verso. Un tercer personaje, Delgado, sólo aparece en II, I-III (73 versos) y hace tres observaciones, siete palabras en total. Creo que tres personajes de este tipo son cosa extraordinaria. Cabría pensar que hubo una versión anterior, en la cual sus papeles eran más extensos.

Los editores se muestran - y con razón- escépticos respecto a la fecha que adjudicó Cotarelo al Amor médico ( 1625 ), pero no ofrecen otra solución. En su edición de Tirso, doña Blanca de los Ríos propone la fecha de I62 I, por razones que ella expondrá en el segundo volumen. E1 porcentaje de romance $(44.9 \%)$ y silva $(3.06 \%)$ indica claramente que la obra es posterior a 1620 , y, a juzgar por la versificación, hasta podría ser de 1625 . Por razones que no puedo divulgar, la pieza probablemente no se escribió antes de los últimos meses de r622. La fecha sería, pues, I $622-\mathrm{I} 625$.

Para Averigüelo Vargas doña Blanca de los Ríos da, en la página cVIII de su edición, la fecha de $162 \mathrm{I}$; en la página 300 habla de 16 I 9 , y en la página I 28 , de I6I9-I62I. La verdadera fecha bien podría estar entre esos años. La obra contiene sólo un $14.6 \%$ de romance, pero $32.6 \%$ de quintillas. Después de $\mathrm{r} 620$ el porcentaje más alto de quintillas en Tirso parece ser el de $19.6 \%$ de La prudencia en la mujer, I62 Ir623. En el acto III, escena II de Averigüelo Vargas (versos 240 I-2407) una alusión a los privados y a su caída segura parecería fijar el terminus a quo en octubre de I6r8. En I, vi (verso 734) se menciona una lechuguilla para hombre; éstas se prohibieron en marzo de 1623 . La mención de las valonas de las mujeres, en I, I (verso $35^{6}$ ), tiene fecha menos segura: las mujeres usaban valonas desde antes de octubre de $\mathrm{I}_{62} \mathrm{I}^{1}$. Las fechas extremas de esta obra son probablemente I6r8-i622. A juzgar por su versificación, también esta pieza pudo haberse escrito mucho antes, y su autor puede haberla retocado hacia r 620 .

En la página xvi escriben los editores: "Damos en nota las variantes principales que ofrecen estas reimpresiones sobre las ediciones primitivas".

1 Cf. en Ruth L. Kennedy, Certain phases of the sumptuary decrees of 1623 , $H R, \mathrm{X}, 1942$, pág. II 4 , la carta de Almansa del 14 de octubre de I621. 
Las demás variantes de Hartzenbusch están en El amor médico, versos 298, 2191, 2290, 2727, 3157 y 3198; y en Averigüelo Vargas, versos r 209, 2390 y 2444. Faltan también las siguientes diéresis del texto de Hartzenbusch de $E l$ amor médico, necesarias para el metro: verso i 74, gradüado; verso $2 \mathrm{I} 33$, rüines; verso $26 \mathrm{I} 7$, visüales: verso 2673 , espiritüales; verso 3446 , jüicio. En la nota al verso 2668 de esta misma obra los editores afirman haber suprimido el que intercalado por Hartzenbusch. En mi ejemplar (Madrid, r 850) no hay tal que.

He encontrado las siguientes erratas: pág. Ix, verso 6 , no es $I 624$ sino 1627; pág. 29, verso 64I, no medió sino me dió; pág. 89, verso 2 192, falta una $a$ adelante de castelhanos; pág. 124, verso 3141 , léase ocupações; pág. 148 , verso 80 , no babeais sino babeáis; pág. 1 57 , penúltima línea de la nota, no 62 sino 162 ; pág. 167 , verso 581 , vuélvome debe escribirse vuelvomé; pág. 185 , nota al verso 1050 , añádase 238 , 255; pág. 202, la primera nota corresponde al verso 1488 , no al 1487 ; pág. 253 , nota, añádase 238,255 ; pág. 232 , verso 2376 , debería haber signo de interrogación después del admiráis.

Si el libro arriba reseñado parece haberse hecho con cierta precipitación, la edición de Por el sótano y el torno se ha hecho evidentemente con amor. No es sólo un libro atractivo, con su hermoso formato, sus bellas láminas y su excelente impresión, sino que su texto está magnínicamente editado y abundantemente anotado. El índice de voces comentadas abarca 196 palabras, para sola esta comedia. Además, sus notas, con definiciones y citas de otras obras, son exhaustivas: juego de cañas, por ejemplo, tiene un comentario de 76 líneas; ventas, de 50. El afán de perfección no se ha visto amenguado por limitación alguna de espacio.

El prólogo ocupa $4^{8}$ páginas. Las primeras $3 \mathbf{I}-$ diez de las cuales se dedican a citas de esta y otras comedias de Tirso- consisten en un ensayo sobre el autor, dividido en seis partes: I) "Leyendo a Tirso, poeta", que se ocupa de sus excelencias líricas; 2) "E1 contraste": "frente a la ternura poética ... la gracia gruesa de los diálogos bufonescos"; 3) "La pintura de interiores", que describe la elaboración de lo que la Srta. McClelland llamaría "escenas laterales", pero desde un punto de vista más pictórico que dramático, ya que las compara con los cuadros de Velázquez, Vermeer y Pieter de Hooch; 4) "Madrid, hermoso abismo", que trata de la pormenorizada presentación de la Calle de Carretas en que se desarrolla la obra: "desde la puerta silenciosa se ve todo el bullicio de la capital"; 5) "Rapidez, cinematografía" (ya Menéndez Pidal ha dicho de Lope que muchas de sus comedias podrían ser perfectos cinedramas); y 6) "Una voz portuguesa": los versos portugueses de la comedia no son digresiones, sino elementos esenciales para el espíritu de la escena. En las tres páginas subsiguientes se enumeran las ediciones anteriores de la comedia, se explica la preparación de su texto y se discute su fecha. El editor acepta la fecha de la profesora Kennedy: r623. En el Resumen de la versificación hay un error: el tercer acto no comienza con 85 versos de quintillas, sino con 55 versos de quintillas y 30 de décimas. Diez páginas de bibliografía completan el prólogo; contiene 220 títulos, entre ellos 40 comedias de Tirso, 28 de Lope, y casi todos los 
artículos de investigadores norteamericanos sobre Tirso. Los únicos de importancia no incluidos que recuerdo son los de Gerald $\mathrm{E}$. Wade en $M L N$, XLIX, I934, págs. I 3-ı 8, y $H R$, VII, I939, págs. 69-72; y los de Ruth Lee Kennedy publicados en $H R$, XII, I944, págs. 49-57, y PMLA, LXIII, I948, págs. I I 3 I-I I 90.

El prólogo se lee con sumo agrado. En él se examina el aspecto barroco de Tirso con gran claridad, por medio de breves análisis de algun as escenas.

Aún hubiera podido intentarse, quizá, determinar hasta qué punto las características que se mencionan como típicas de Tirso son en realidad peculiares de él, y en qué medida son comunes a todos los dramaturgos de la época. Los estudios sobre la comedia no están, probablemente, lo bastante adelantados para que se pueda resolver esta cuestión, y, sin embargo, es de lamentarse que el editor no haya procurado hacerlo, a base de las muchas comedias que examinó. Buena parte de lo que se dice en el prólogo podría aplicarse igualmente a Lope de Vega. Quizá el único rasgo no generalizable es "el contraste entre la ternura poética y la gracia gruesa", contraste tan frecuente en Tirso y mucho más raro, probablemente, en Lope.

En la bibliografía hubiera sido mejor diferenciar las siglas de las dos ediciones académicas de Lope de Vega. El abanillo, "Acad. III", no está en la misma edición que Los comendadores de Córdoba, "Acad. XI".

Pocos son los errores. Sólo he hallado una errata: pág. I 38 , nota al verso I 500, no Early sino Earle. Debería haber diéresis en crüel, verso I082, y en confianza, verso I32I. Hartzenbusch hace notar que en ei verso 20 I 5 hay que pronunciar viudos para mantener la asonancia, y que el verso 2694 ha sido "suplido por el editor de la Colección general de comedias escogidas". A estas cuestiones no se alude en la presente edición.

La entrada de doña Bernarda en el primer acto recuerda la del comendador en Peribáñez, y otras semejantes en La honra por la mujer de Lope, El médico de su honra de Calderón y Audiencias del rey don Pedro de autor desconocido.

Cambridge, Mass.

Courtney Bruerton

\section{Alfonso García Valdecasas, El hidalgo y el honor. Editorial Revista de Occidente, Madrid, I 948. 253 págs. + 8 láminas.}

Más de treinta años han pasado desde las fundamentales investigaciones de Américo Castro sobre la idea de la honra española ${ }^{\mathrm{I}}$. Ningún trabajo posterior sobre el tema ha tenido su magnitud ni su importancia, a pesar de que el mismo título de Algunas observaciones ... indica que este magistral estudio no tuvo el propósito de agotar la materia, ni siquiera para la época a que deliberadamente se limitó: los siglos xvi y xvII.

1 Algunas observaciones acerca del concepto del honor en los siglos xvi y xvii, $R F E$, III, I9I6, págs. I-5o y 357-386. 